\title{
Comunicação/Communication
}

\section{Superdosagem da vacina 17DD contra febre amarela, em uma região do sul do Brasil}

\section{Overdose of yellow fever vaccine in the Southern region of Brazil}

\author{
Marcelo Carneiro $^{1,2}$, Beanir da Silva Lara ${ }^{3}$, Betina Schimidt ${ }^{4}$ e Lediana Gais ${ }^{4,5}$
}

\section{RESUMO}

Introdução: A febre amarela é uma arbovirose prevenível por uma vacina eficaz e segura. Métodos: Acompanhamento clínico prospectivo de 49 pessoas que receberam uma superdosagem equivocada de vacina contra febre amarela, durante o surto de 2009, em uma localidade rural do Vale do Rio Pardo, no interior do Rio Grande do Sul. Resultados: Durante os 45 dias de acompanhamento clínico, em apenas 1 (2,1\%) caso houve a manifestação de um possível viscerotropismo agudo leve, como evento adverso pós-vacinal. Conclusões: No grupo de pessoas acompanhadas, após a superdosagem de vacina antiamarílica, percebeu-se a quase total inexistência de eventos adversos.

Palavras-chaves: Febre amarela. Vacina antiamarílica. Arbovirose.

\begin{abstract}
Introduction: Yellow fever is a preventable disease when using a safe, effective vaccine. Methods: A prospective clinical follow-up of 49 people who received an overdose of the wrong vaccine against yellow fever during the 2009 outbreak in a rural area of the Vale do Rio Pardo, State of Rio Grande do Sul. Results: During 45 days of clinical follow-up, only 1 (2.1\%) case presented manifestations of a possible acute viscerotropism as an adverse postvaccination event. Conclusions: In the group of people monitored following an overdose of anti-yellow fever vaccine, observation confirmed almost total absence of adverse events.
\end{abstract}

Keywords: Yellow fever. Yellow fever vaccine. Arbovirus.

No Brasil, nos últimos anos, a febre amarela silvestre (FAS) ocorreu como epidemias e epizootias em várias regiões do país ${ }^{1,2}$. No Rio Grande do Sul (RS), os últimos casos em humanos datavam de 1966 , quando houve vacinação em toda a região noroeste do estado. Desde 2001, tem-se notificado ocorrência de morte em primatas não humanos (PNH) e, em 2003, esta região do estado com 43 municípios, foi redefinida como área de transição, o que acarretou na cobertura vacinal da população residente e de viajantes, com reestruturação das formas de vigilância epidemiológica. Entre outubro de 2008 e julho de 2009, verificou-se 2.054 mortes de PNH, em 151 municípios, dos

1. Controle de Infecção e Epidemiologia Hospitalar, Hospital Santa Cruz, Santa Cruz do Sul, RS. 2. Departamento de Biologia e Farmácia, Curso de Medicina, Universidade de Santa Cruz do Sul, Santa Cruz do Sul, RS. 3. Vigilância Epidemiológica e de Imunizações, 13a Coordenadoria Regional de Saúde do Rio Grande do Sul, Santa Cruz do Sul, RS. 4. Serviço de Vigilância Sanitária de Vera Cruz, Prefeitura Municipal de Vera Cruz, Vera Cruz, RS. 5. Curso de Enfermagem, Universidade de Santa Cruz do Sul, Santa Cruz do Sul, RS.

Endereço para correspondência: Dr. Marcelo Carneiro. R. Thomaz Flores 887/301, Centro, 96810-090 Santa Cruz do Sul, RS.

Telefax: $55513713-7484$

e-mail: carneiromarcelo@yahoo.com.br

Recebido para publicação em 10/01/2010

Aceito em 04/11/2010 quais houve confirmação de epizootia em 61, o que desencadeou uma campanha de vacinação em 293 municípios do RS, além do reforço da vigilância contra novas epizootias. De novembro de 2008 a maio de 2009, confirmou-se 19 casos de FAS com letalidade de 36,8\% ( 7 casos) no RS ${ }^{3}$. Na região de Santa Cruz do Sul (13 a Coordenadoria Regional de Saúde), com 335.197 habitantes, que até 2009 era indene para febre amarela ${ }^{4}$, foram notificados 11 (57,9\%) casos de FAS e uma letalidade de 18,2\% (2 casos). A indicação de vacinação contra FA, nesta região, foi definida a partir da confirmação dos casos em humanos, antes da confirmação da epizootia, diferentemente do que aconteceu no restante do estado. A campanha de vacinação em massa, nesta regional, aplicou um total de 269.033 doses, obtendo uma cobertura vacinal de $80,3 \%$, ou seja, mantendo a possibilidade de casos autóctones na Região do Vale do Rio Pardo5.

Entre março e abril de 2009, ou seja, entre a 9a e $17^{\text {a }}$ semana epidemiológica, na vigência do surto de FA silvestre, notificou-se a ocorrência da aplicação inadvertida de 10 vezes a dose padronizada da vacina 17DD contra FA, da Bio-Manguinhos, devido a troca de diluente, na região de Santa Cruz do Sul, RS. O lote da vacina foi 089VFB020Z e o do diluente foi 083DFA020Z. Após a confirmação do ocorrido em 49 (100\%) pessoas vacinadas, decidiu-se fazer um acompanhamento clínico em todos, e laboratorial (hematologia e bioquímica) apenas nos casos sintomáticos, durante 45 dias. O acompanhamento clínico constou de história clínica e exame físico com atenção direcionada aos sinais de alerta relacionados à doença viscerotrópica aguda. A média de idade foi de 42 anos ( $\mathrm{DP} \pm 36,8)$, com uma variação de 4-89 anos. O gênero masculino foi predominante em $27(55,1 \%)$ casos. Nenhuma das pessoas vacinadas apresentava qualquer contraindicação para a vacinação. Durante o acompanhamento clínico, apenas $1(2,1 \%)$ paciente necessitou de atendimento hospitalar de urgência: uma menina de 6 anos de idade que, dois dias após a vacinação, passou a apresentar dor abdominal, vômitos e um episódio de hipertermia (não aferida). Os exames complementares estavam em parâmetros dentro da normalidade (leucócitos 7.200 células $/ \mathrm{mm}^{3}$, hemoglobina 12,7g/dl, bilirrubinas totais $0,9 \mathrm{~g} / \mathrm{dL}$, tempo de protrombina $12 \mathrm{~s}$, INR 1,1). O tratamento foi ambulatorial e sintomático, com resolução dos sintomas em dois dias. A intercorrência pode ser considerada como uma manifestação de viscerotropismo leve.

O uso de superdosagem de vacina antiamarílica resultou em quase inexistência de eventos adversos às pessoas vacinadas, como verificado por Rabello cols ${ }^{6}$. Ressalta-se a necessidade de supervisão rigorosa de profissional técnico especializado no preparo de vacinas. 


\section{CONFLITO DE INTERESSE}

Os autores declaram não haver nenhum tipo de conflito de interesse no desenvolvimento do estudo.

\section{REFERÊNCIAS}

1. Vasconcelos PFC. Yellow fever. Rev Soc Bras Med Trop 2003; 36:275-293.

2. Souza RP, Foster PG, Sallum MAM, Coimbra TLM, Maeda AY, Silveira VR, et al. Detection of a New Yellow Fever Virus Lineage Within the South American Genotype I in Brazil. J Med Virol 2010; 82:175-185.

3. Centro Estadual de Vigilância em Saúde do Rio Grande do Sul. Boletim Semanal do dia 22/04/2009. Febre amarela silvestre no Rio Grande do Sul, 2008 e 2009. [acessado em 01 março 2010]. Disponível em http://www.saude.rs.gov.br/wsa/ portal/index.jsp)/.

4. Ministério da Saúde. Manual de vigilância epidemiológica da febre amarela. Brasília: Fundação Nacional de Saúde; 1999.

5. Ministério da Saúde. Boletim de Atualização de Dezembro de 2009. Febre Amarela. [acessado em 01 março 2010]. Disponível em http://portal.saude.gov. br/portal/arquivos/pdf/boletim_febre_amarela_09_12_09.pdf/.

6. Rabello A, Orsini M, Disch J, Marcial T, Leal MLF, Freire MS, et al. Low frequency of side effects following an incidental 25 times concentrated dose of yellow fever vaccine. Rev Soc Bras Med Trop 2002; 35:177-180. 